\title{
Design, construction, and in vitro analysis of A33scFv::CDy, a recombinant fusion protein for antibody-directed enzyme prodrug therapy in colon cancer
}

\author{
VÂNIA COELHO ${ }^{1}$, JENS DERNEDDE ${ }^{2}$, ULF PETRAUSCH ${ }^{1}$, HOSSEIN PANJIDEH ${ }^{2}$, HENDRIK FUCHS ${ }^{2}$, \\ CHRISTOPH MENZEL ${ }^{3}$, STEFAN DÜBEL ${ }^{3}$, ULRICH KEILHOLZ ${ }^{1}$, ECKHARD THIEL $^{1}$ and P. MARKUS DECKERT ${ }^{1}$ \\ ${ }^{1}$ CharitéCentrum für Tumormedizin, Medizinische Klinik mit Schwerpunkt Hämatologie und Onkologie CBF; \\ ${ }^{2}$ CharitéCentrum für Labormedizin, Institut für Klinische Chemie und Pathobiochemie, 12200 Berlin; \\ ${ }^{3}$ Technical University of Braunschweig, Institute of Biochemistry and Biotechnology, D-38106 Braunschweig, Germany
}

Received February 14, 2007; Accepted April 2, 2007

\begin{abstract}
Antibody-directed enzyme-prodrug therapy (ADEPT) aims at improving the specificity of conventional chemotherapy by employing artificial antibody-enzyme constructs to convert a non-toxic prodrug into a cytotoxic agent specifically localized to the tumor site. The gpA33 antigen is a promising target for ADEPT in colon cancer, as it is expressed by $>95 \%$ of human colon cancers, but is absent in all non-gastrointestinal tissues. We designed a recombinant fusion construct of a phage display-generated anti-gpA33 single chain fragment, $\mathrm{A} 33 \mathrm{scFv}$, with cytosine deaminase from yeast (CDy), which converts 5-fluorocytosine (5-FC) into 5-fluorouracil (5-FU). The resulting construct, A33scFv::CDy, was overexpressed in Pichia pastoris and secreted into culture supernatant. The fusion protein was purified by affinity chromatography on protein L. Silver-staining after SDSpolyacrylamide gel electrophoresis confirmed molecular mass and purity. Antibody binding and specificity were quantified by flow cytometry. The complete ADEPT system was applied in vitro on gpA33-positive LIM1215 cells, assessing cell survival by a fluorescein diacetate assay. Cytotoxicity of the
\end{abstract}

Correspondence to: Dr P. Markus Deckert, Charité - Campus Benjamin Franklin, Hindenburgdamm 30, D-12200 Berlin, Germany E-mail: markus.deckert@charite.de

Abbreviations: 5-FC, 5-fluorocytosine; 5-FU, 5-fluorouracil; ADEPT, antibody-directed enzyme-prodrug therapy; CDy, yeast cytosine deaminase; GFP, green fluorescent protein; gpA33, glycoprotein A33; huA33, humanized A33 antibody, respectively; $\mathrm{IgG}$, immunoglobulin class $\mathrm{G}$; PCR, polymerase chain reaction; $\mathrm{scFv}$, recombinant single chain protein comprising the two variable fragments of an antibody; BMGY, buffered complex medium containing glycerol; BMMY, buffered minimal medium containing methanol; PMSF, phenylmethylsulfonyl fluoride

Key words: tumor targeting, A33 antibody, antibody-directed enzyme-prodrug therapy, colon carcinoma, recombinant fusion proteins prodrug 5-FC after A33scFv::CDy binding was equimolar to that of 5-FU, and this effect depended specifically on both antibody and enzyme function. These results demonstrate bifunctional activity of the heterogeneous Pichia-produced A33scFv::CDy fusion protein and proof of principle for the ADEPT system proposed herein.

\section{Introduction}

Monoclonal antibodies have become an accepted modality of cancer therapy. Recombinant antibodies and antibody-based fusion proteins hold the promise of further extending the therapeutic possibilities of this modality. Single chain variable fragments ( $\mathrm{scFv}$ ) consist of the variable regions of an antibody's heavy and light chains fused together via a flexible linker, whose length determines the quaternary structure. Thus, they carry the complete antigen binding site in a single polypeptide chain of only about $30 \mathrm{kDa}$. In tumor targeting, scFv have demonstrated excellent tumor penetration, high ratios of tumor to normal tissue concentration, and low background $(1,2)$. This makes them attractive targeting components of bifunctional fusion proteins such as those needed for antibodydirected enzyme-prodrug therapy (ADEPT). In ADEPT, after binding of an antibody-enzyme construct to the cognate tumor antigen, the enzyme component converts a prodrug into a cytotoxic drug, thus generating drug activity specifically in tumor tissue $(3,4)$.

Several ADEPT systems have shown promising in vivo efficacy in a number of tumor models (5) and in several xenograft systems in nude mice $(4,6-8)$, demonstrating in principle that ADEPT can target tumor tissue with high selectivity and deliver chemotherapeutic drugs with high intratumoral concentrations.

Senter's group first used bacterial cytosine deaminase for ADEPT to catalyze the deamination of 5-fluorocytosine (5-FC), which is non-toxic in mammals, into 5-fluorouracil (5-FU) (9). Clinical studies on ADEPT have proven the rationale for its application in humans (10).

An eminent obstacle to the development of scFv-based approaches, however, is posed by the expression of a heterogeneous protein consisting of human antibody sequences 
and e.g. a bacterial enzyme in a single expression system. Methylotrophic Pichia yeasts such as P. pastoris combine the simple handling of microbial cultures with the posttranslational processing of eukaryotes and thus offer an interesting alternative for large-scale expression of complex proteins $(11,12)$.

In this work we report on the design, cloning, expression and in vitro characterization of a new recombinant antibodyenzyme fusion protein for ADEPT, termed A33scFv::CDy.

The A33 monoclonal antibody recognizes a newly characterized cell-surface differentiation antigen of approximately $43 \mathrm{kDa}$ that belongs to the immunoglobulin superfamily. It is expressed on normal human gastrointestinal epithelium and on $>95 \%$ of primary or metastatic colon cancers, but is absent in most other normal tissues (13).

Radiolabelled humanized A33 antibody has been shown to selectively target primary and metastatic tumor sites of colorectal cancers and to penetrate to the center of large necrotic metastatic lesions, indicating potential therapeutic use of gpA33 as a target for colorectal cancer therapy (14).

As opposed to the quoted work from Senter's and previous results from our group (15), here we used cytosine deaminase from Saccharomyces cerevisiae (CDy) rather then Escherichia coli (CD), as this isoenzyme promised higher levels of expression yield and catalytic activity.

\section{Materials and methods}

Design and cloning of plasmids A33scFv::CDy [pPIC9K] and A33scFv::CDy [pPICZ $\alpha A]$. By PCR cloning, the cDNA sequences encoding A33scFv (16) and CDy were amplified. CDy cDNA was amplified from the commercial vector pORF-Fcy (Invivogen, San Diego, USA) and flanked by unique restriction sites (NotI and SpeI) with the primer pair Fcy5' (5'-CCTCAACTAGTGGTGGAGGTGGAAGTGTGACA GGGGGAATGGCAAGC-3') and Fcy3' (5'-GGCGAATTA ATTCGCGGCCGCTTACTCACCAATATCTTCAAACCA ATCCTGAGG-3'). Fifty cycles of PCR were performed with incubations for $30 \mathrm{sec}$ at $95^{\circ} \mathrm{C}, 50 \mathrm{sec}$ at $50^{\circ} \mathrm{C}$ and $1 \mathrm{~min}$ at $72^{\circ} \mathrm{C}$. After gel extraction and purification using the Qiagen Gel extraction kit, the amplified cDNA was initially subcloned into the pPCR Blunt II vector (Invitrogen) to generate pPCR BluntII CDy. Identity and integrity of the cloned fragment were confirmed by automated DNA sequencing (ABI PRISM 310, Perkin-Elmer, USA). The A33scFv::CDy fragment was excised by digestion with the restriction endonucleases AvrII and SpeI and ligated with T4 ligase into the pPICZ $\alpha \mathrm{A}$ or pPIC9K backbones (Invitrogen) to yield the plasmid vectors A33scFv::CDy [pPICZ $\alpha \mathrm{A}$ ] and A33scFv::CDy [pPIC9K], respectively. The common cloning cassette and maps of the resulting vectors are shown in Fig. 1.

Transformation, selection and screening for fusion protein expression. Pichia pastoris KM71 (Invitrogen) was grown in YPD (1\% yeast extract, $2 \%$ peptone, $2 \%$ dextrose) and made electrocompetent following the procedure described by the manufacturer (17). Eighty microliters of electrocompetent KM71 cells were mixed with $5 \mu \mathrm{g}$ of either A33scFv::CDy [pPICZ $\alpha \mathrm{A}$ ] or A33scFv::CDy [pPIC9K] linearized by digestion with PmeI, and then electroporated by a pulse discharge of
A

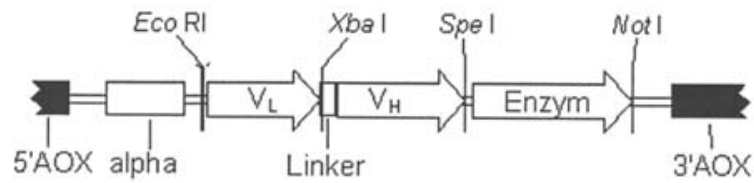

B

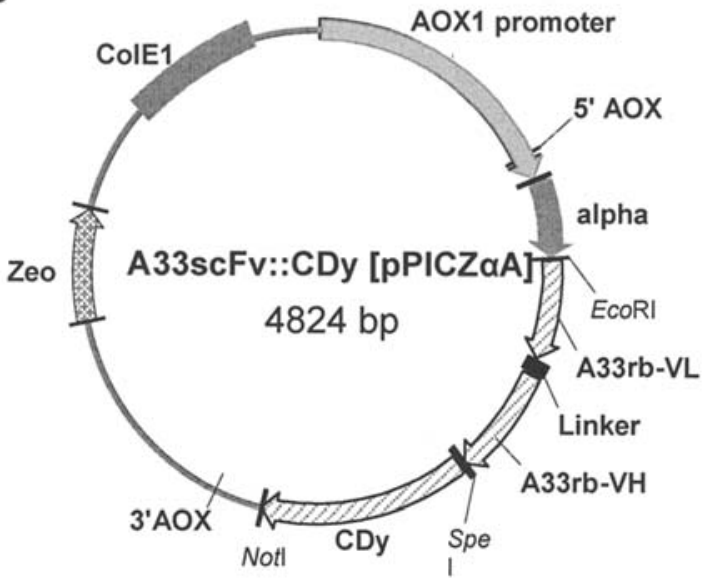

C

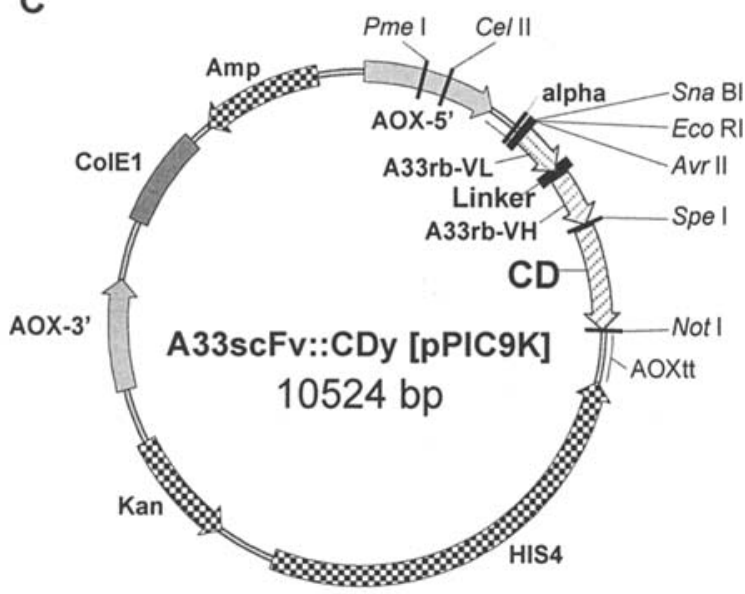

Figure 1. Plasmid design and cloning strategy. A, Common cloning site of pPICZ $\alpha \mathrm{A}$ and $\mathrm{pPIC} 9 \mathrm{~K}$ vectors with insertion cassette for the scFv-fusion protein with relevant restriction sites. B and C, Vector constructs based on pPIC9K and pPICZ $\alpha$ A. Restriction sites are designated in italics. AOX 5', AOX 3', promotor and terminal region of the native AOX-1 gene, respectively; 5'AOX, 3' AOX, AOX-1 gene flanking primers; A33rbVL, A33rbVH, position of the variable regions of the light and heavy antibody chains, respectively; CDy, cytosine deaminase from yeast; linker, artificial linking sequence; alpha, alpha mating factor secretion signal; Amp, Kan, Zeo, resistance genes against ampicillin, kanamycin, and Zeocin, respectively; His4, histidine deaminase; ColE1, E. coli replication factor.

$1500 \mathrm{~V}, 25 \mu \mathrm{F}$, and $400 \Omega$ (Bio-Rad Gene Pulser) for 5 min. After pulsing, $500 \mathrm{ml}$ of ice-cold $1 \mathrm{M}$ sorbitol was immediately added to each cuvette. Transformant aliquots of $400 \mu 1$ each were spread on YPDS plates (1\% yeast extract, $2 \%$ peptone, $2 \%$ glucose, $1 \mathrm{M}$ sorbitol, $2 \%$ agar), which contained $100 \mu \mathrm{g} / \mathrm{ml}$ of Zeocin for pPICZ $\alpha$ A transformants.

PPIC9K-transformed clones were selected for their ability to grow on histidine deficient medium, indicating presence of the HIS4 gene transferred with successful vector trans- 
formation. These $\mathrm{HIS}^{+}$colonies were replica-plated onto plates containing the antibiotic G418 in concentrations from 2 to $10 \mathrm{mg} / \mathrm{ml}$. Finally, in clones resistant to G418 the genomic integration of the transfected gene was checked by PCR (primer sequences available upon request). Clones carrying the $\mathrm{A} 33 \mathrm{scFV}:: \mathrm{CDy}$ sequence were grown in $5 \mathrm{ml} \mathrm{BMGY}$ medium (1\% yeast extract, $2 \%$ peptone, $100 \mathrm{mM}$ potassium phosphate, $\mathrm{pH} 6.0,1.34 \%$ YNB, $4 \times 10^{-5 \%}$ Biotin, $1 \%$ glycerol) in a $50 \mathrm{ml}$ conical tube overnight at $30^{\circ} \mathrm{C}$ and $350 \mathrm{rpm}$ agitation. After centrifugation at $3,000 \mathrm{~g}$ for $10 \mathrm{~min}$ at $20^{\circ} \mathrm{C}$, the cell pellet was resuspended in $5 \mathrm{ml}$ of BMMY medium (1\% yeast extract, $2 \%$ peptone, $100 \mathrm{mM}$ potassium phosphate, $\mathrm{pH} 6.0,1.34 \% \mathrm{YNB}, 4 \times 10^{-5} \%$ Biotin, $1 \%$ methanol) to induce protein expression. The cells were incubated for 3 days at $30^{\circ} \mathrm{C}$ and $350 \mathrm{rpm}$, and fresh methanol was added to a total of $1 \%$ every $24 \mathrm{~h}$ to maintain induction.

Clones transformed with the pPICZ $\alpha \mathrm{A}$-construct grown on YPDS-Zeocin plates were directly inoculated in $500 \mu 1$ BMGY on a 96-well plate and incubated overnight at $30^{\circ} \mathrm{C}$ and $350 \mathrm{rpm}$. The plate was then centrifuged at $1500 \mathrm{~g}$ for $10 \mathrm{~min}$ at $20^{\circ} \mathrm{C}$, and cell pellets were resuspended in $500 \mu 1$ of BMMY to induce protein expression. Induction was maintained for $72 \mathrm{~h}$ as described above.

Detection of fusion protein-producing transformants. With pPIC9K-transformants, cleared supernatant samples were obtained from each induced culture, and samples were analyzed by electrophoresis on $10 \%$ SDS polyacrylamide gels (SDSPAGE) under denaturating conditions, followed by electroblotting onto a nitrocellulose membrane (Amersham Pharmacia Biotech, Freiburg, Germany). CDy was then detected by sequential membrane incubation with a 1:2,000 dilution of polyclonal anti-CDy IgG from sheep (Acris, Hiddenhausen, Germany) and a 1:500 dilution of peroxidaseconjugated anti-sheep IgG (Sigma, St. Louis, USA), developed using the ECL detection kit (Amersham Pharmacia Biotech) and documented photographically. Stained gels and immunoblots were photographed and quantitatively analyzed using the AlphaEase FC software (AlphaInnotech, San Leandro, CA).

To detect expression of the fusion protein in clones transformed with the pPICZ $\alpha$ A-based construct, 96-well Nunc Maxisorp plates were coated with $100 \mathrm{ng} /$ well of recombinant $\mathrm{IgG}$-grafted A33 expressed in $\mathrm{CHO}$ cells (data not shown) in $100 \mu 1$ of coating buffer. After washing, the plates were incubated with supernatants from induced Pichia clones for $1 \mathrm{~h}$ at room temperature, followed by incubation with Protein L-HRP (Pierce, Rockford, USA) diluted 1:5,000 in blocking solution for $1 \mathrm{~h}$ at $37^{\circ} \mathrm{C}$. The reaction was stopped with $100 \mu \mathrm{l} /$ well of $1 \mathrm{~N} \mathrm{H}_{2} \mathrm{SO}_{4}$ and the reaction was quantified colorimetrically at $655 \mathrm{~nm}$ using a 96-well plate photometer (Tecan Sunrise, Crailsheim, Germany).

Clones with a signal in the top tenth of the distribution range were selected for inoculation of $20 \mathrm{ml}$ each of BMGY to an $\mathrm{OD}_{600 \mathrm{~nm}}$ of 0.6 and incubated overnight at $30^{\circ} \mathrm{C}$ and $250 \mathrm{rpm}$. Cells were harvested by centrifugation and resuspended in $10 \mathrm{ml} \mathrm{BMMY}$. Expression was induced as described above, and culture samples were examined for production of the fusion protein by SDS-PAGE and protein staining as with pPIC9K-transformed clones.
Optimization of fusion protein production. Overnight cultures of fusion protein-producing clones were used to inoculate $20 \mathrm{ml} \mathrm{BMGY} \mathrm{pH} 6.0$ to an $\mathrm{OD}_{600 \mathrm{~nm}}$ of 0.6 , incubated overnight at $30^{\circ} \mathrm{C}$ and $250 \mathrm{rpm}$, harvested by centrifugation and resuspended in $20 \mathrm{ml}$ BMMY for subsequent methanol induction under various conditions as indicated in the results. Samples were collected from the induced cultures at different time-points and analyzed after purification with protein $\mathrm{L}$ (Pierce).

Production of A33scFv::CDy. High-expressing clones selected for protein production were grown in a culture volume of $100 \mathrm{ml}$ each in a 11 baffled shake flask overnight at $220 \mathrm{rpm}$ and $30^{\circ} \mathrm{C}$. The cells were harvested by centrifugation and were used to inoculate a total of 11 of BMGY, divided into two baffled shake flasks of 21 volume to give a starting $\mathrm{OD}_{600 \mathrm{~nm}}$ of 0.5 . After overnight culture at $30^{\circ} \mathrm{C}$ and $220 \mathrm{rpm}$, the cells were harvested at a final $\mathrm{OD}_{600 \mathrm{~nm}}$ of $\sim 40$ by centrifugation at $1500 \mathrm{~g}$ and $25^{\circ} \mathrm{C}$ for $10 \mathrm{~min}$, resuspended in $11 \mathrm{BMMY}$ and divided in two baffled 21 flasks. Expression was then induced at $25^{\circ} \mathrm{C}$ and maintained for $60 \mathrm{~h}$ by adding $5 \mathrm{ml}$ of $100 \%$ methanol every $24 \mathrm{~h}$. Supernatant was subsequently collected by centrifugation as described, and sterile filtered.

Purification of A33scFv::CDy. Five tablets of proteinase inhibitor cocktail (Roche, Mannheim, Germany) were added per liter of Pichia culture supernatant to reduce proteolysis. The A33scFv::CDy fusion protein was then purified by affinity chromatography on sepharose-immobilized protein L plus (Pierce) via gravity flow. Each elution was performed with $800 \mu 1$ of $0.1 \mathrm{M}$ glycin buffer $\mathrm{pH} 2.5$. To each elution fraction $200 \mu \mathrm{l}$ of $1 \mathrm{M}$ Tris-buffer $\mathrm{pH} 9.0$ was added to adjust the $\mathrm{pH}$ to $\sim 6.0$.

Flow cytometry. LIM1215 colon cancer cells (provided by the Ludwig Institute for Cancer Research, New York, USA) were harvested and resuspended in $10 \mathrm{ml}$ Dulbecco's PBS. Viable cells were counted after staining an aliquot 1:2 (v/v) with trypan blue. Aliquots of 500,000 cells were entered in $1.5 \mathrm{ml}$ microcentrifuge tubes and incubated with the fusion protein to be tested.

After 40-min incubation at $37^{\circ} \mathrm{C}$ with shaking, cells were washed twice with $500 \mu 1$ Dulbecco's PBS, and resuspended in $250 \mu 1$ of Dulbecco's PBS. To detect A33scFv::CDy directly, cells were subsequently incubated with FITC-labelled polyclonal anti-CDy (Acris, Hiddenhausen, Germany) in a dilution of 1/160 for $15 \mathrm{~min}$ and washed again. For inhibition assays, cells were incubated with A33scFv::GFP for $40 \mathrm{~min}$ instead. Physical parameters and fluorescence of 30,000 events each were measured using a FACScalibur instrument (BectonDickinson, Heildelberg, Germany).

Cytotoxicity assay. Cytotoxicity was determined in vitro using the fluorescein diacetate assay as described by Nygren et al (18). Briefly, 2,000 cells each of LIM1215 cells were transferred to a 96-well culture plate and grown to confluence. After washing twice with PBS, the fusion protein to be tested was added to a final volume of $200 \mu \mathrm{l}$ in RPMI with $10 \% \mathrm{v} / \mathrm{v}$ FCS and incubated at $37^{\circ} \mathrm{C}$ with $0.5 \% \mathrm{CO}_{2}$ and incubated for $3 \mathrm{~h}$. Cells were washed twice with PBS, the drug or prodrug 
to be tested was added in fresh cell culture medium (RMPI1640 supplemented with $10 \%$ heat inactivated FCS and $1 \%$ penicillin/streptavidin) at the concentrations indicated, and the cells were incubated for $48 \mathrm{~h}$ at $37^{\circ} \mathrm{C}$ with $0.5 \% \mathrm{CO}_{2}$. Cells were finally washed twice with PBS and incubated in $10 \mu \mathrm{l} / \mathrm{ml}$ fluorescein diacetate (Sigma) for $45 \mathrm{~min}$. Fluorescence was measured by a Spectra Max Gemini microplate reader (Molecular Devices, Ismaning, Germany) with excitation and emission wavelengths of 485 and $538 \mathrm{~nm}$, respectively. Including the controls $C$, cells without drug, and $B$, sample without cells, the survival index $(S I)$ was calculated from the sample fluorescence (Test) and expressed in percent using the following formula:

$$
S I(\%)=\frac{\text { Test }-B}{C-B} \times 100
$$

\section{Results}

Design and construction of A33scFv::CDy. A vector system for the production of $\mathrm{scFv}$ ::effector fusion proteins comprising two functional cassettes with flanking unique restriction sites that allow for the independent exchange of each component by restriction digest and ligation was designed and cloned. Based on the commercial plasmid backbones pPIC9K and $\mathrm{pPICZ} \alpha \mathrm{A}$, two transformation vectors were thus generated, leading to identical integrants by omega-insertion into the genome of the transformed Pichia strain KM71. Both plasmids put expression of the fusion protein under control of the AOX I promoter located downstream of the $\alpha$-factor signal sequence to obtain extracellular secretion of the protein (12).

Screening of Pichia transformants for expression. Several sequential assays were necessary to select clones transformed with the pPIC9K-based A33scFv::CDy vector construct. First, exploiting the ability to grow on histidine deficient media conferred by the pPIC9K backbone, KM71 Pichia were screened for presence of the insert (18), followed by incubation on media with increasing concentrations of G418 to select for kanamycin resistance. Quantitative differences in kanamycin resistance are conferred by multiple insertions of the Kan gene, which was linked to the inserted construct DNA, thus allowing to detect multi-copy integrants.

Finally, the genomic integration of the transfected gene was analyzed and confirmed by PCR (data not shown). Fifty clones revealed genomic integration of the A33scFV::CDy DNA sequence. Six out of these 50 clones displayed high expression of the protein construct in 5-ml screening induction and immunoblot.

The vector backbone pPICZ $\alpha \mathrm{A}$ allowed for a simplified selection procedure. Conferring Zeocin resistance, this vector allowed the selection of hyper-drug resistant transformants containing multiple copies of the expression cassette in one step. Therefore, all clones growing on YPDS-Zeocin plates were directly analyzed for expression.

Culture supernatants from a total of $93 \mathrm{pPICZ} \alpha \mathrm{A}$ clones were screened by ELISA, of which 91 were found to exhibit binding to immobilized recombinant gpA33. Clones showing a binding signal in the top tenth of the distribution range were induced in 5-ml pilot cultures, and their supernatants further
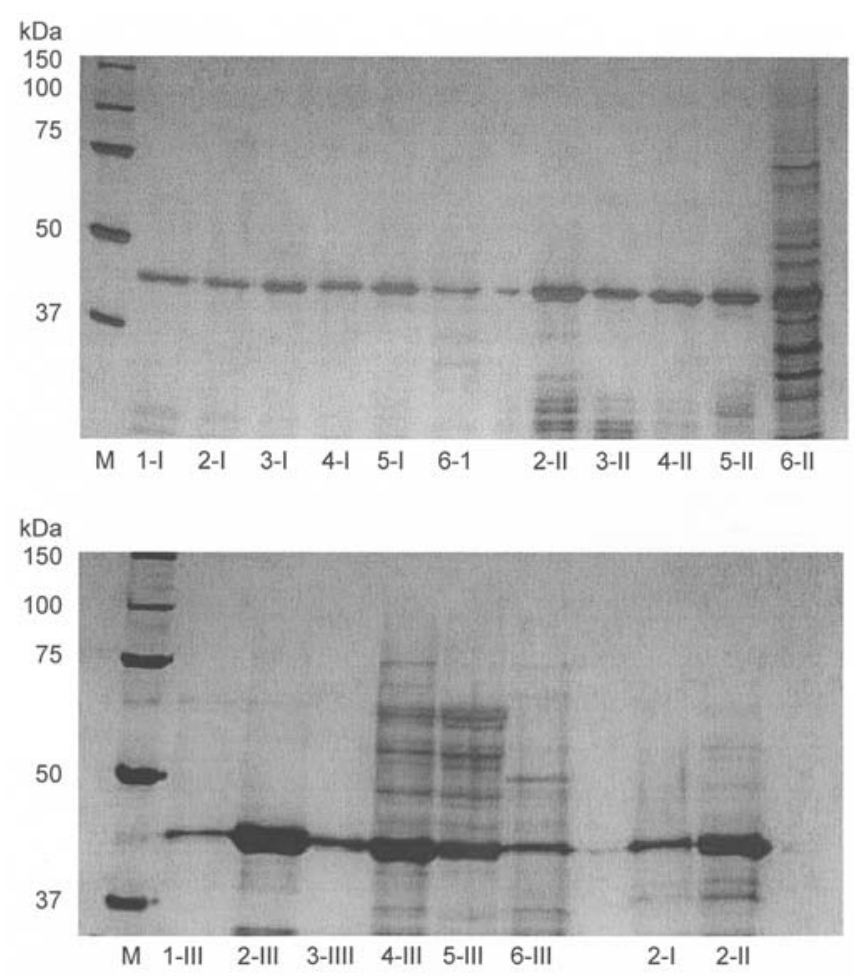

Figure 2. Optimization of expression yield and postexpressional stability. SDS-PAGE. Eluates from protein L affinity chromatography of A33scFv:: CDy-containing supernatants induced under the following conditions indicated by Arabic numerals: 1 , induction at $30^{\circ} \mathrm{C} ; 2$, induction at $25^{\circ} \mathrm{C}$, both without additives; 3 , temperature $30^{\circ} \mathrm{C}$ and addition of $10 \mathrm{mM}$ EDTA; 4 , temperature $30^{\circ} \mathrm{C}$ and addition of $1.45 \mu \mathrm{M}$ Pepstatin $\mathrm{A}+0.5 \mathrm{mM}$ PMSF; 5 , temperature $25^{\circ} \mathrm{C}$ and addition of $1.45 \mu \mathrm{M}$ Pepstatin $\mathrm{A}+0.5 \mathrm{mM}$ PMSF; 6 , temperature $30^{\circ} \mathrm{C}$ with culture stopped at an $\mathrm{OD}_{600 \mathrm{~nm}}$ of 6 . Samples were taken for analysis at the following time-points indicated by Roman numerals: I, 24 h; II, 48 h; III, 72 h. M, molecular weight marker.

analyzed by SDS-PAGE and silver staining, confirming the expected size of the construct, but also revealing various amounts of degradation products (see also Fig. 3), which prompted optimization studies prior to scaling up of production.

Expression optimization of A33scFv::CDy. Aliquots from a high-producing $\mathrm{pPICZ} \alpha \mathrm{A}$ clone were cultivated in parallel under different conditions and analyzed by silver-stained SDS-PAGE at various time-points as indicated in Fig. 2. At a cultivation temperature of $25^{\circ} \mathrm{C}$ degradation turned out to be lowest. In addition, adding protease inhibitor further reduced protein degradation.

Production at laboratory scale. A high-producing pPICZ $\alpha$ Atransformant Pichia clone was selected for further expression experiments based on the data gained from the pilot expressions above. Silver-stained SDS-PAGE revealed a strong uniform band corresponding to the expected size of the fusion protein of $47 \mathrm{kDa}$. In addition, two weak but distinct bands were consistently visible, which corresponded to degradation products of proteolysis, presumably in the linker region. After purification by centrifugation filtration and protein $\mathrm{L}$ affinity chromatography, reducing SDS-PAGE of the eluate reproducibly revealed three remaining contaminant bands (Fig. 3), whose proportion among the total protein, however, was $\leq 5 \%$ as determined by electronic image analysis. The 


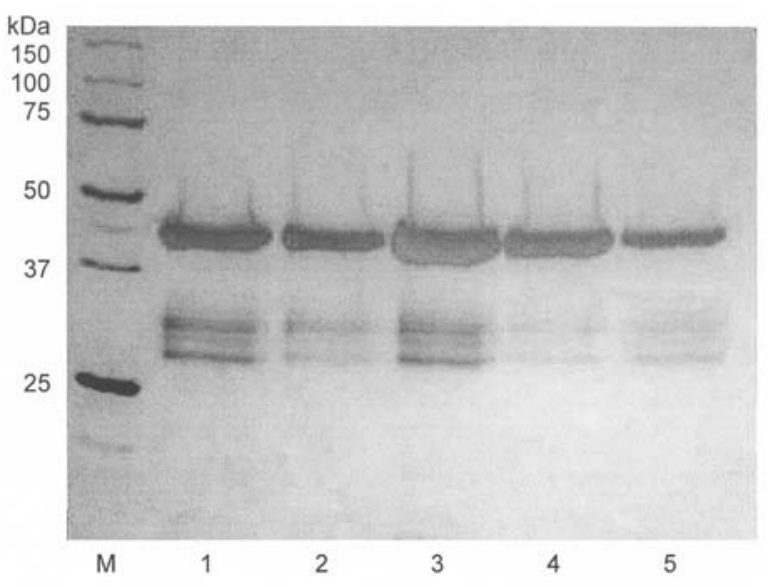

Figure 3. Expression and purification of A33scFv::CDy at the 11 scale SDS-PAGE. Lanes 1-5 show eluates from different protein $\mathrm{L}$ purification runs of 11 expression culture supernatant each. All lanes show various amounts of degradation products.

total yield after purification was about $500 \mu \mathrm{g}$, corresponding to $1.0 \mathrm{mg}$ purified protein per liter of culture.

Antigen-binding activity of A33scFv::CDy. The binding activity and specificity of the expressed recombinant antibody were verified by flow cytometry on gpA33-positive LIM1215 colon cancer cells (19). In a direct assay, binding of A33scFv::CDy was detected by a secondary antibody (Fig. 4A), demonstrating binding activity of both crude supernatant and purified fusion protein. To evaluate binding specificity in an inhibition assay, a fluorescent A33scFv-based fusion protein, A33scFv::GFP, was directly detected, and $\mathrm{A} 33 \mathrm{scFv}:$ :CDy was used to block its binding to gpA33-positive LIM1215 cells. Here, binding of the fluorescent fusion protein could be quantitatively suppressed by the A33scFv::enzyme fusion protein, demonstrating immunologically specific binding.

$A D E P T$ system in vitro. To test for the dual activity of the A33scFv::CDy fusion protein and to determine its suitability

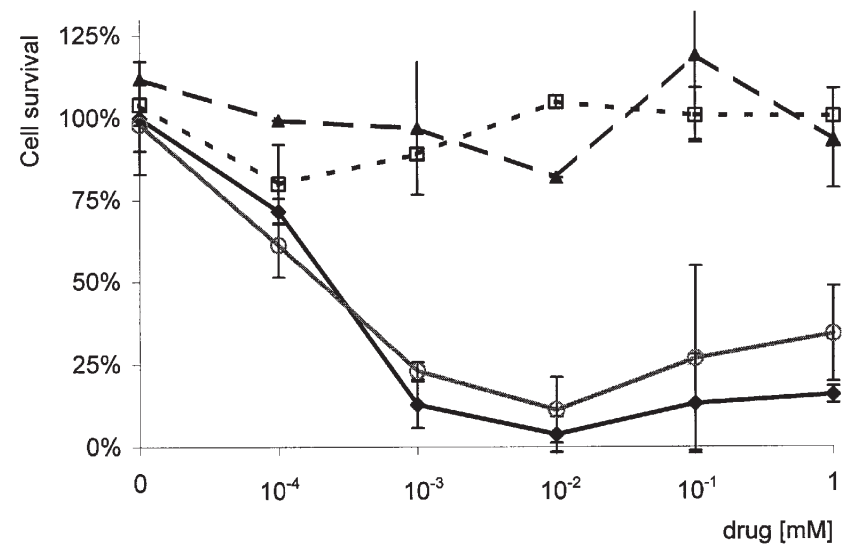

Figure 5. A33scFv::CDy mediates cytotoxicity of 5-FC on gpA33 antigenpositive cells depending on prodrug dose. LIM1215 cells were incubated with $10 \mathrm{ng} / \mathrm{ml}$ of fusion protein and, after washing, with a dilution series of the prodrug. Cell survival was determined by fluorescein diacetate assay. 5-FC alone (open squares) and after pre-incubation with the control construct A33scFv::GFP (closed triangels) had no effect on cell survival. After pre-incubation with A33scFv::CDy (open circles), however, 5-FC had approximately the same cytotoxic effect as equimolar amounts of 5-FU (closed carets). Mean and standard deviation of triplicate samples.

for the prodrug therapy approach, a fluorescein diacetate cytotoxicity assay of the complete ADEPT system was established.

To establish the difference in cytotoxicity between drug and prodrug, LIM1215 cells were incubated with dilution series of either 5-FU or 5-FC alone, confirming the toxicity of 5-FU as previously reported (15) and the complete lack thereof with 5-FC in the dose range tested (Fig. 5). In the same assay, pre-incubation of 5-FC with the fusion protein reduced the cell survival curve to that of 5-FU. After preincubation with a control fusion protein, however, 5-FC had no effect on cell survival.

The effect of the fusion protein on cell survival was also quantified by dilution series. In a control without prodrug incubation, A33scFv::CDy had no cytotoxic effect of its own. With subsequent 5-FC incubation, $1 \mathrm{ng} / \mathrm{ml}$ of fusion
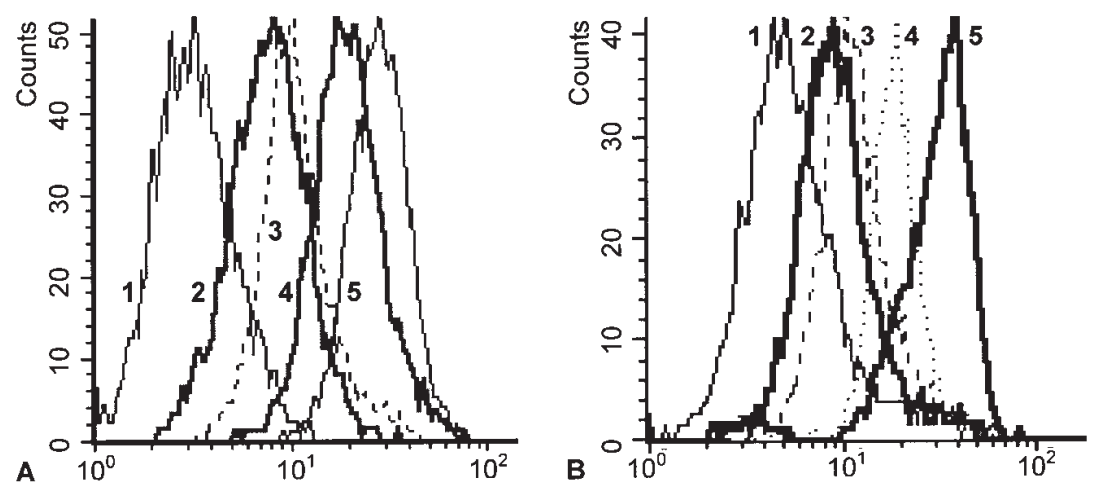

Figure 4. Flow cytometry: A33scFv::CDy binding to gpA33-positive cells. A, LIM1215 single-cell suspension was incubated with A33scFv::CDy and, after washing, with a FITC-labelled anti-CDy antibody. Crude supernatant (4) and purified A33scFv::CDy (5) showed a clear signal over cells alone (1) and incubation with either A33scFv::CDy alone (2) or anti-CDy FITC antibody alone (3). B, Binding competition with A33scFv::GFP. LIM1215 single-cell suspension (negative controls in PBS buffer, 1, and BMMY supernatant medium, 2) was incubated with A33scFv::GFP (positive control, 5) and analyzed by flow cytometry. Preincubation of the cells with $\mathrm{A} 33 \mathrm{scFv}:: \mathrm{CDy}$ reduced subsequent $\mathrm{A} 33 \mathrm{scFv}:$ GFP binding quantitatively $(3$, saturation; 4, half-saturation). 


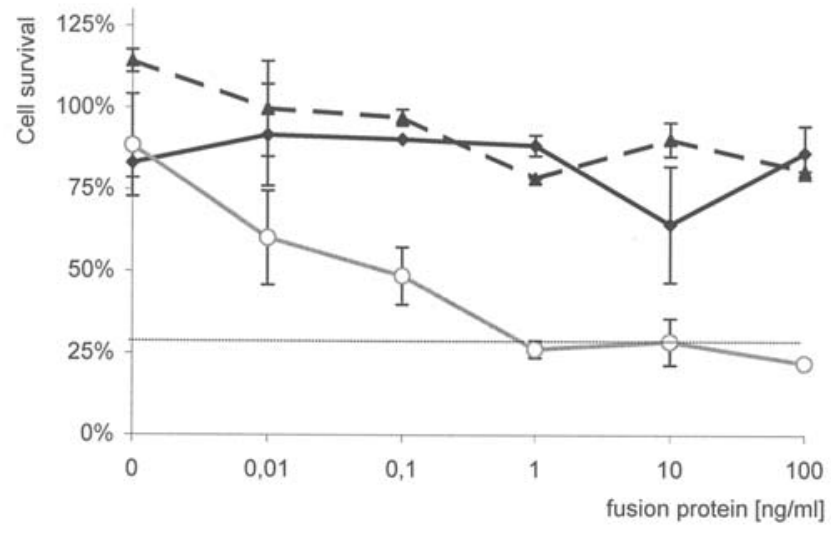

Figure 6. A33scFv::CDy mediates cytotoxicity of 5-FC on gpA33 antigenpositive cells depending on fusion protein dose. LIM1215 cells were incubated with a dilution series of the A33scFv::CDy fusion protein and, after washing, with $100 \mathrm{nM} 5$-FC prodrug (open circles), demonstrating dose-dependent cytotoxicity. A33scFv::CDy construct alone without subsequent 5-FC incubation (closed triangels) had no cytotoxic effect, nor had pre-incubation with excess control protein A33scFv::GFP prior to A33scFv::CDy and subsequent 5-FC incubation (closed carets). Dotted line, equimolar 5-FU control. Mean and standard deviation of triplicate samples.

protein was sufficient to reach the maximum cytotoxic effect in this assay. Saturation of gpA33 binding sites by excess A33scFv::GFP prior to the incubations with A33scFv::CDy and subsequently with 5-FC completely removed the cytotoxic effect of this ADEPT system.

\section{Discussion}

In this report, we describe the design, expression, and in vitro characterization of a novel fusion protein for ADEPT, termed A33scFv::CDy. Recombinant fusion proteins promise to overcome the limitations of chemical conjugates for ADEPT, i.e. instability of the chemical linker and the inevitable presence of products with various component ratios. The heterogeneous sources of such fusion proteins, i.e. the antibody's mammalian and the enzyme's microbial origin, however, make it often difficult if not impossible to express a functional fusion protein in a single expression host. This may be due to the presence or absence of suitable chaperones, but also to the intrinsic capacities of a given expression system such as posttranslational processing or susceptibility to intracellular product effects on the host cell.

For their ability to secrete correctly folded and glycosylated proteins into the supernatant of an easy-to-handle microbial culture, thus offering advantages over both bacterial and mammalian expression systems, methylotrophic Pichia yeasts have been used to produce a wide range of recombinant proteins including antibody fragments $(12,20)$.

We previously reported the expression of a very similar fusion protein for ADEPT, A33scFv::CD with cytosine deaminase from E. coli (15). There, E. coli was also the expression host, requiring recovery from inclusion bodies and resulting in a culture yield of about $100 \mu \mathrm{g} / \mathrm{l}$. Elaborate attempts to reach a higher yield by production in $P$. pastoris, however, failed because bacterial CD could not be expressed or excreted by the yeast (unpublished data). In addition, for yeast CD higher catalytic activity in biological systems had been reported in comparison to the bacterial isoenzyme (23). These reasons prompted us to redesign an $\mathrm{A} 33 \mathrm{scFv}$ fusion protein with cytosine deaminase from yeast.

Producing the new fusion protein in Pichia yeast, we obtained about ten times the expression yield as in bacteria, with approximately $1 \mathrm{mg} / \mathrm{l}$ in shake flask cultures. Secretion into culture supernatant greatly facilitated protein retrieval and purification, and the protein was functional in supernatant without further purification. By single-step affinity chromatography on protein L, sufficient purity for pre-clinical experiments was achieved.

However, there was partial degradation of the protein even after purification, indicated by additional bands around a molecular size of $30 \mathrm{kDa}$. The size suggesting cleavage in the linker region, we tried to narrow down potential specific proteases in Pichia, but could not identify a matching cleavage site in public databases. Still, recloning the linker region in future constructs could possibly avoid proteolysis and generate a uniform band under all circumstances. However, for all practical purposes, reducing the culture temperature, adding a protease inhibitor mixture, and speeding the processing procedures solved this problem (21).

Although the transformation method employed led to genomic integration of the gene of interest (as opposed to bacterial expression plasmids), the choice of transformation vector was of influence beyond cloning and selection. To maximize protein expression, integration of multiple copies of the gene of interest is desirable. Of the two transformation vectors employed here, $\mathrm{pPICZ} \alpha$ appeared to result in a higher number of multi-copy clones. In addition, it has been reported that the large size of the pPIC9K vector may lead to less stable transformants (22), so that we finally selected a pPICZ $\alpha$ transformant for production.

The secreted protein was bifunctionally active without any further treatment, i.e., even the uncleared culture supernatant could directly be used for the detection of A33-positive cells in flow cytometry or for in vitro ADEPT. Binding specificity was demonstrated by quantitative blocking of A33scFv::GFP binding to gpA33-positive cells after their pre-saturation with A33scFv::CDy in flow cytometry. Finally, the complete ADEPT system was proven in principle by cytotoxicity assays which, in conclusion, demonstrate that 5-FC is specifically toxified by A33scFv::CDy depending both on antibody binding and enzyme activity. With A33scFv::fusion protein in excess, 5-FC was rendered equally toxic to equimolar amounts of 5-FU. While these results largely match those obtained with the previous fusion protein based on bacterial CD (23), our results also appear to confirm the theoretical background for which the yeast isoenzyme was interesting in the first place: with A33scFv::CDy, $1 \mathrm{ng} / \mathrm{ml}$ sufficed to induce maximal cytotoxicity, whereas the corresponding value for the bacterial CD-construct was 10 times higher. While we could not compare the two constructs directly because no fresh bacterial fusion protein was available for this study, the order of magnitude of this difference makes it unlikely that this is a mere incidental finding. The improved results with the yeast protein may be attributable both to higher catalytic activity of the homodimerically active yeast enzyme (24) and to higher quality of the Pichia-produced protein due to better folding and functional secretion. 


\section{Acknowledgements}

This work was supported by an Ernst-von-Leyden Stipendium of the Berliner Krebsgesellschaft to V.C. and by Deutsche Krebshilfe grant no. 1072981 to P.M.D. and H.F.

\section{References}

1. Yokota T, Milenic DE, Whitlow M and Schlom J: Rapid tumor penetration of a single-chain $\mathrm{Fv}$ and comparison with other immunoglobulin forms. Cancer Res 52: 3402-3408, 1992.

2. Begent RH, Verhaar MJ, Chester KA, Casey JL, Green AJ, Napier MP, Hope-Stone LD, Cushen N, Keep PA, Johnson CJ, Hawkins RE, Hilson AJ and Robson L: Clinical evidence of efficient tumor targeting based on single-chain Fv antibody selected from a combinatorial library. Nat Med 2: 979-984, 1996.

3. Napier MP, Sharma SK, Springer CJ, Bagshawe KD, Green AJ, Martin J, Stribbling SM, Cushen N, O'Malley D and Begent RH: Antibody-directed enzyme prodrug therapy: efficacy and mechanism of action in colorectal carcinoma. Clin Cancer Res 6: 765-772, 2000.

4. Bagshawe KD: Antibody-directed enzyme prodrug therapy for cancer: its theoretical basis and application. Mol Med Today 1: 424-431, 1995.

5. Senter PD and Springer CJ: Selective activation of anticancer prodrugs by monoclonal antibody-enzyme conjugates. Adv Drug Deliv Rev 53: 247-264, 2001.

6. Sharma SK, Bagshawe KD, Springer CJ, Burke PJ, Rogers GT, Boden JA, Antoniw P, Melton RG and Sherwood RF: Antibody directed enzyme prodrug therapy (ADEPT): a three phase system. Dis Markers 9: 225-231, 1991.

7. Springer CJ, Bagshawe KD, Sharma SK, Searle F, Boden JA, Antoniw P, Burke PJ, Rogers GT, Sherwood RF and Melton RG: Ablation of human choriocarcinoma xenografts in nude mice by antibody-directed enzyme prodrug therapy (ADEPT) with three novel compounds. Eur J Cancer 27: 1361-1366, 1991.

8. Eccles SA, Court WJ, Box GA, Dean CJ, Melton RG and Springer CJ: Regression of established breast carcinoma xenografts with antibody-directed enzyme prodrug therapy against c-erbB2 p185. Cancer Res 54: 5171-5177, 1994.

9. Wallace PM, MacMaster JF, Smith VF, Kerr DE, Senter PD and Cosand WL: Intratumoral generation of 5-fluorouracil mediated by an antibody-cytosine deaminase conjugate in combination with 5-fluorocytosine. Cancer Res 54: 2719-2723, 1994.

10. Martin J, Stribbling SM, Poon GK, Begent RH, Napier M, Sharma SK and Springer CJ: Antibody-directed enzyme prodrug therapy: pharmacokinetics and plasma levels of prodrug and drug in a phase I clinical trial. Cancer Chemother Pharmacol 40: 189-201, 1997.

11. Powers DB, Amersdorfer P, Poul M, Nielsen UB, Shalaby MR, Adams GP, Weiner LM and Marks JD: Expression of singlechain Fv-Fc fusions in Pichia pastoris. J Immunol Methods 251: 123-135, 2001.

12. Fischer R, Drossard J, Emans N, Commandeur U and Hellwig S: Towards molecular farming in the future: pichia pastoris-based production of single-chain antibody fragments. Biotechnol Appl Biochem 30: 117-120, 1999.
13. Sakamoto J, Kojima H, Kato J, Hamashima H and Suzuki H: Organ-specific expression of the intestinal epithelium-related antigen A33, a cell surface target for antibody-based imaging and treatment in gastrointestinal cancer. Cancer Chemother Pharmacol 46 (Suppl.): S27-S32, 2000.

14. Scott AM, Lee FT, Jones R, Hopkins W, MacGregor D, Cebon JS, Hannah A, Chong GUP, Papenfuss A, Rigopoulos A, Sturrock S, Murphy R, Wirth V, Murone C, Smyth FE, Knight S, Welt S, Ritter G, Richards E, Nice EC, Burgess AW and Old LJ: A phase I trial of humanized monoclonal antibody A33 in patients with colorectal carcinoma: biodistribution, pharmacokinetics, and quantitative tumor uptake. Clin Cancer Res 11: 4810-4817, 2005 .

15. Deckert PM, Renner C, Cohen LS, Jungbluth A, Ritter G, Bertino JR, Old LJ and Welt S: A33scFv-cytosine deaminase: a recombinant protein construct for antibody-directed enzymeprodrug therapy. Br J Cancer 88: 937-939, 2003.

16. Rader C, Ritter G, Nathan S, Elia M, Gout I, Jungbluth AA, Cohen LS, Welt S, Old LJ and Barbas CF III: The rabbit antibody repertoire as a novel source for the generation of therapeutic human antibodies. J Biol Chem 275: 13668-1376, 2000 .

17. Invitrogen. A Manual of Methods for Expression of Recombinant Proteins in Pichia pastoris. http://www.invitrogen.com/content/ sfs/manuals/pich man.pdf [Catalog no K1710-01]. 1-11-2002.

18. Nygren P, Fridborg H, Csoka K, Sundstrom C, De La TM, Kristensen J, Bergh J, Hagberg H, Glimelius B and Rastad J: Detection of tumor-specific cytotoxic drug activity in vitro using the fluorometric microculture cytotoxicity assay and primary cultures of tumor cells from patients. Int J Cancer 56: 715-720, 1994.

19. Heath JK, White SJ, Johnstone CN, Catimel B, Simpson RJ, Moritz RL, Tu GF, Ji H, Whitehead RH, Groenen LC, Scott AM, Ritter G, Cohen L, Welt S, Old LJ, Nice EC and Burgess AW: The human A33 antigen is a transmembrane glycoprotein and a novel member of the immunoglobulin superfamily. Proc Natl Acad Sci USA 94: 469-474, 1997.

20. Pennell CA and Eldin P: In vitro production of recombinant antibody fragments in Pichia pastoris. Res Immunol 149: 599-603, 1998 .

21. Macauley-Patrick S, Fazenda ML, McNeil B and Harvey LM: Heterologous protein production using the Pichia pastoris expression system. Yeast 22: 249-270, 2005.

22. Daly R and Hearn MT: Expression of heterologous proteins in Pichia pastoris: a useful experimental tool in protein engineering and production. J Mol Recognit 18: 119-138, 2005.

23. Kievit E, Bershad E, Ng E, Sethna P, Dev I, Lawrence TS and Rehemtulla A: Superiority of yeast over bacterial cytosine deaminase for enzyme/prodrug gene therapy in colon cancer xenografts. Cancer Res 59: 1417-1421, 1999.

24. Ireton GC, Black ME and Stoddard BL: The 1.14 A crystal structure of yeast cytosine deaminase: evolution of nucleotide salvage enzymes and implications for genetic chemotherapy. Structure 11: 961-972, 2003. 